\title{
Pollen Allergy Suppression Effect by the Oral Administration of Acetic Acid Bacteria (Gluconacetobacter hansenii)
}

\author{
HIROYUKI INAGAWA ${ }^{1,2}$, TAKASHI NISHIZAWA ${ }^{3}$, CHIE KOCHI $^{3}$, \\ SATOKO AMANO ${ }^{3}$ and GEN-ICHIRO SOMA ${ }^{1,2}$ \\ ${ }^{1}$ Control of Innate Immunity, Technology Research Association, Kagawa, Japan; \\ ${ }^{2}$ Research Institute for Healthy Living, Niigata University of Pharmacy and Applied Life Sciences, Niigata, Japan; \\ ${ }^{3}$ Macrophi Inc., Kagawa, Japan
}

\begin{abstract}
Background/Aim: Gluconacetobacter hansenii ( $G$. hansenii) is an acetic acid bacterium of vinegar production. Its anti-allergic effect on mice upon oral administration was examined. Materials and Methods: The amount of LPS was measured by the Limulus reaction. Mice were sensitized by peritoneal and intranasal administration of cedar pollen and alum followed by oral administration of 30 or $150 \mathrm{mg} / \mathrm{kg}$ of heated $\mathrm{G}$. hansenii cells. Pollen was administered intranasally to evaluate nasal symptoms, and at 8 weeks, IgE and IL-10 levels in blood were measured by ELISA. Results: The amount of LPS in dried bacterial cells was $10.4 \pm 3.3 \mathrm{mg} / \mathrm{g}$. In the cedar pollinosis model of mice, a significant reduction was observed in nose scratching of both groups administered with the bacterial cells $(30,150 \mathrm{mg} / \mathrm{kg})$. Conclusion: $G$. hansenii contains LPS, and its oral administration showed an anti-allergic effect by a significant mitigation of the symptoms in a pollen allergy mouse model.
\end{abstract}

Across the world, vinegar is manufactured using acetic acid bacteria which ferment alcohol into acetic acid (1). In the age-old manufacturing method, acetic acid bacteria, which are aerobic bacteria, form a bacterial film on the alcohol surface and metabolize alcohol to acetic acid. It is believed that the bacterial cell bodies dissolve in the manufactured product during the maturing process to produce rich vinegar with improved flavor. In other words, vinegar which is being produced since ancient times is considered to contain not only acetic acid, which is a

Correspondence to: Dr. Hiroyuki Inagawa, Control of Innate Immunity, Technology Research Association, 2217-16 FROMKAGAWA Bio Lab., Hayashi-cho, Takamatsu-shi, Kagawa-ken, 7610301, Japan. Tel/Fax: +81 878139203, e-mail: pina@shizenmeneki.org

Key Words: Hay fever, lipopolysaccharide, acetic acid bacteria, immunity. metabolite of alcohol, but also cell components. Vinegar is believed to have functional properties, and acetic acid is known to be the functional ingredient (1). Although matured vinegar contains substances derived from acetic acid bacterial cells, very few studies have been conducted on functional ingredients derived from bacterial cell bodies.

Acetic acid bacteria are Gram-negative bacteria, and it has been reported that they contain almost as much lipopolysaccharides (LPS) as the Gram-negative bacteria that are known as immunostimulatory, and that they induce macrophage activation $(2,3)$. Hashimoto et al. have revealed that vinegar produced by the age-old method contains LPS, a macrophage activating component (4).

In recent years, it has been discovered that oral intake of LPS contained in food has an immunopotentiating effect (5). Oral administration of LPS, derived from Pantoea agglomerans bacteria which is a plant symbiotic bacterium, for one week to mice enhances the phagocytic ability of peritoneal macrophages (6). Also, the amount of LPS in brown rice is large (7), and it has been reported that brown rice intake improves liver function in obese mice (8). In human intervention studies, the intake of Pantoea agglomerans LPS and Salacia tea has been reported to lower LDL, improve HbAlc (9), and enhance the density of peripheral blood capillaries (10). From the above, the acetic acid bacteria with a history of safe use can be considered to have functions of LPS.

We discovered that oral administration of killed acetic acid bacteria cells freshly isolated from persimmon can prevent cedar pollinosis onset in mice (11). However, the useful biological activity of LPS as a functional ingredient of acetic acid bacterial cell bodies has not been made clear. In this study, to confirm the immunopotentiating function of G. hansenii (12), acetic acid bacteria, their LPS content and innate immune activity, the effect of oral administration of the acetic acid bacterial cell bodies for treating pollen allergy were investigated. 


\section{Materials and Methods}

Preparation of acetic acid bacteria. G. hansenii were obtained from Kewpie Corporation, Tokyo, Japan. The bacteria were cultured at $30^{\circ} \mathrm{C}$ with a medium containing sugar, yeast extract, and ethanol (13). G. hansenii were collected by centrfugation of the culture at $10,000 \mathrm{rpm}$ for $4 \mathrm{~min}$ at $5^{\circ} \mathrm{C}$. The bacteria were washed twice by the addition of a 10 -fold amount $(\mathrm{w} / \mathrm{w})$ of a citrate buffer solution $(\mathrm{pH} 4)$, followed by sufficient stirring and centrifugation as described above. The final bacterial concentrate was lyophilized to yield a powder. The LPS amount in samples was assayed by the kinetic turbidimetric method with a Toxinometer ET-6000J (Wako Pure Chemical Industries Ltd. Tokyo, Japan, standard LPS: Escherichia coli UKT-B) as described previously (7).

Production of nitric oxide. RAW 264.7 cells were suspended in RPMI 1640 supplemented with $10 \%$ fetal bovine serum, penicillin $(100 \mathrm{U} / \mathrm{ml})$, and streptomycin $(100 \mu \mathrm{g} / \mathrm{ml})$, and $1.6 \times 10^{5}$ cells were added to 96-well plate, to which attenuated Pantoea agglomerans LPS or acetic acid bacteria sample, (i) Cultured and harvested $G$. hansenii cells directly freeze-dried (control), (ii) Cultured and collected $G$. hansenii cells freeze-dried after heat-killing $\left(80^{\circ} \mathrm{C}, 1\right.$ min) without adjusting the $\mathrm{pH}(\mathrm{pH} 4$ to 5), (iii) Cultured and harvested $G$. hansenii cells ( $\mathrm{pH} 4$ to 5) neutralized by adjusting the $\mathrm{pH}(\mathrm{pH} 7)$ before heat-killing and freeze-dried after heat-killing $\left(80^{\circ} \mathrm{C}, 1 \mathrm{~min}\right)$, was added, and the supernatant was collected after 20 hours. To $50 \mu \mathrm{l}$ of the supernatant, an equal amount of Griess reagent ( $1 \%$ sulfanilamide, $0.1 \%$ naphthyl ethylenediamine, $2.5 \%$ aqueous phosphoric acid) was added to measure the nitrate concentration.

Pollen allergy test. BALB/c female mice were fed American Institute of Nutrition-93, and intraperitoneally administered a suspension containing Japanese Cedar, Cryptomeria japonica, and Pollen Crude Extract (SLS Co, Tokyo, Japan) at $10 \mu \mathrm{g} / 200 \mu \mathrm{l}$ and alum (Imject Alum; Thermo Scientific, Waltham, MA, USA) three times at 0, 3 and 7 days. The control group received a PBS solution. Next, an antigen solution of the cedar pollen extract was intranasally administered into the nostrils of the mice at $0.15 \mu \mathrm{g} / 5 \mu \mathrm{l}$ at days 14 to 28 . For sorting the test groups, blood was collected from the fundus of the mice on day 28 after starting the study, and total serum immunoglobulin E (IgE) levels were measured by Mouse IgE ELISA $\mathrm{MAX}^{\mathrm{TM}}$ standard (Biolegend Inc., San Diego, CA, USA). At day 30, the immunized mice were divided into three groups based on the $\operatorname{IgE}$ concentration. The heat-killed cells of $G$. hansenii were suspended in pure water and orally administered to mice by a feeding needle at $0,30,150 \mathrm{mg} / \mathrm{kg}$ mouse weight/day at days 30 to 58 . The intranasal sensitization was restarted at day 37 and continued until day 58. At day 44 , the antigen solution of the cedar pollen extract was again administered intranasally, and the frequency of nose scratching by the mice was counted for $30 \mathrm{~min}(\mathrm{n}=12-15 /$ group $)$. Mice whose body weight had decreased by $20 \%$ or more due to pollen immunity were not included in the experimental group because of ethical considerations. The animal experiments of this study were approved by the Experimental Animal Committee, Control of Innate Immunity Technology Research Association (Approval number: 18-03), and conducted from May 9 to July 20, 2018.

Serum IgE and IL-10, Spleen mRNA expression analysis. At day 58 after starting the study (start of pollen immunization), the mice were bled under anesthesia, and Peyer's patches and spleen were extracted. Serum IgE and IL-10 (Quantikine ELISA Mouse IL-10 (R\&D SYSTEMS) were measured. Isolated Payer's patch and spleen were treated with QIAzol Lysis Reagent (Qiagen Corp., Madison, WI, USA) and then each RNA was extracted by RNeasy Plus Universal Mini kit (Qiagen Corp., Madison, WI, USA).

A total of $3.5 \mu \mathrm{g}$ of the recovered total RNA was used, and decomposition of chromosomal DNA was performed by DNase treatment using the ReverTra Ace ${ }^{\circledR}$ qPCR RT Master Mix with gDNA Remover, according to the instruction manual of this kit, and then cDNA was synthesized by reverse transcription. Quantification of IL-4, IL-10, IFN- $\gamma$, Foxp3, FceR1a and glyceraldehyde-3phosphate dehydro-genase (GAPDH) gene expression were performed for each group using TaqMan real-time quantitative PCR carried out in a real-time QPCR System, Mx3005P (Agilent Technologies, Santa Clara, CA, USA).

Statistical analysis. For statistical comparisons, two-way ANOVA with Bonferroni post-hoc tests was used. All statistical analyses were performed with the Prism 5 software (GraphPad, Software, La Jolla, CA, USA).

\section{Results}

LPS content in G. hansenii cells and cell preparation. The cultured $G$. hansenii cells were extracted by phenol, and the amount of LPS was measured. The average amount of LPS in $G$. hansenii was estimated at $10.4 \pm 3.3 \mathrm{mg} / \mathrm{g} \quad(\mathrm{n}=4$, Standard deviation) of dry bacterial weight. Large amounts of extracellular polysaccharides are present in acetic acidproducing acetic acid bacteria, and depending on the method of preparation of cells, there is a possibility that LPS is not extracted due to the polysaccharides and is degraded upon heating if the $\mathrm{pH}$ of the bacterial cell sample is low (14). Therefore, (i) Sample in which G. hansenii is directly freezedried to reduce the impact of heating (control), (ii) Sample which is freeze-dried following the heat-killing $\left(80^{\circ} \mathrm{C}\right.$, 1 min) without adjusting the $\mathrm{pH}$, (iii) Sample which is neutralized by adjusting the $\mathrm{pH}$ before heat-killing and freeze-dried after heat-killing, were prepared. When the macrophage activation (RAW 246.7 cells) of each bacterial cell sample was evaluated based on NO production ability (Figure 1), there was almost no difference between the three samples, and the second method, which is the most convenient method for preparing killed bacteria, was selected.

Cedar pollinosis suppression effect by oral administration of G. hansenii. In this study, as a symptom alleviation model following the onset of cedar pollinosis, killed G. hansenii cells were administered after performing cedar pollen immunization. The total serum IgE was significantly higher in the immunized group than in the non-immunized control group (Figure 2A). Based on the IgE levels of the cedar pollen immunized group, the 3 categories of mice orally administered with killed $G$. hansenii cells $(0,30,150 \mathrm{mg} / \mathrm{kg})$ 


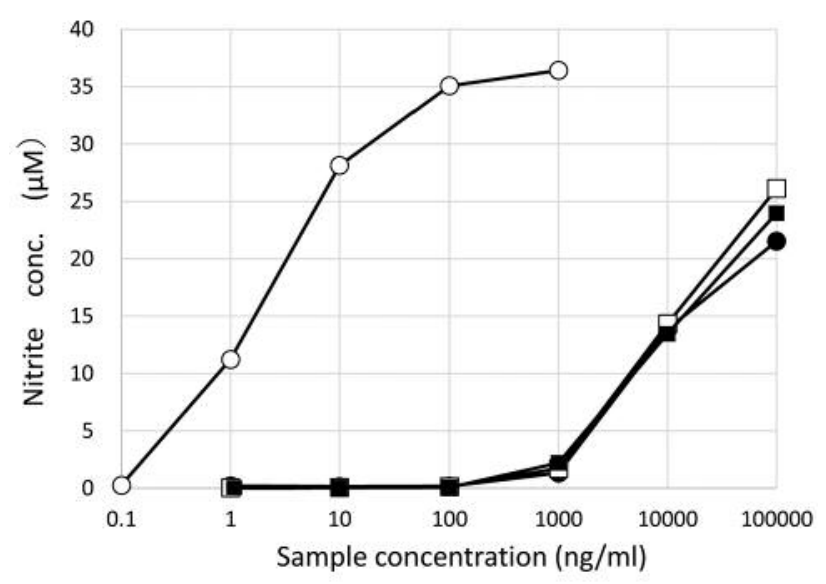

Figure 1. Macrophage activation effect of various $G$. hansenii cell preparation samples. Each sample was added to RAW 246.7 cells, and after $20 \mathrm{~h}$, the amount of $\mathrm{NO}_{2}$ in the supernatant was measured using the Griess reaction. $\bigcirc$ : Positive control (Pantoea agglomerans LPS),

-: Freeze-dried G. hansenii viable cells, $\mathbf{\square}$ : G. hansenii viable cells (pH 4 to 5) freeze-dried after heat-killing, $\square$ : G. hansenii viable cells heat-killed and freeze-dried after neutralization ( $p H 7)$.

were divided into groups such that the average $\operatorname{IgE}$ levels of each group were almost the same (Figure 2A).

Although $G$. hansenii $(0,30,150 \mathrm{mg} / \mathrm{kg})$ was orally administered for 2 weeks, body weight differences and toxic effects were not observed among the four groups on day 44 after starting the study (Figure 2B). When the frequency of nose scratching was measured for $30 \mathrm{~min}$ after intranasal administration of cedar pollen, a significant increase was observed in the frequency of nose scratching in the immunized control group compared to the non-immunized control group, and between groups administered with low dose $(30 \mathrm{mg} / \mathrm{kg})$ and high dose $(150 \mathrm{mg} / \mathrm{kg})$ of $G$. hansenii, an evident suppression in the frequency of nose scratching was observed, which was equivalent to that of the nonimmunized control group (Figure 2C).

The total amount of serum IgE, measured in the blood on the day the frequency of nose scratching was measured, was higher in all the immunized groups compared to the nonimmunized group. Suppression was not observed in the killed G. hansenii cell administration group (Figure 2D).

Cytokine production. Intranasal immunization and administration of killed $G$. hansenii cells were continued for 2 more weeks from the day nose scratching frequency was measured (day 58 from the start of the study), and the levels of IL-10, an immunosuppressive cytokine, were measured in serum of mice of each group. The results indicated that only high doses of $G$. hansenii significantly increased the IL-10 levels (Figure 3A). On the same day, mRNA was extracted from the spleen and Peyer's patches, and IL-4, IL-10, IFN- $\gamma$, Foxp3 and FceR1a gene expression was examined. There was no difference in gene expression among the groups (Figure 3B, C). But in the spleen, IFN- $\gamma$ and FoxP3 gene expression decreased compared to the non-immunized control group, and FceR1a showed a tendency to increase (Figure 3C).

\section{Discussion}

Gluconacetobacter hansenii, a type of acetic acid bacterium, which is used in this study, is used to produce vinegar and has a history of safe use (12). We focused on LPS contained in the bacterial cells as an active ingredient and measured its content and confirmed its biological activity. The LPS content ( $E$. coli LPS conversion based on Limulus activity) purified from $G$. hansenii using the phenol method, which is a common LPS purification method, was $1.0 \pm 0.3 \%$ of dry cell weight. The macrophage activation ability of the $G$. hansenii cells was evaluated by examining their ability to induce production of nitric oxide (NO) by a macrophage cell line that is used as an inflammatory index. The comparative activation (converted to purified LPS) of G. hansenii LPS was about 1/100 times of that of Pantoea LPS, indicating that the $G$. hansenii LPS induces a weak inflammatory response (Figure 1). The LPS content and macrophage activation effect of the bacterial cells showed properties similar to those of acetic acid bacterium Gluconobacter suboxydans isolated from persimmon (11). It has also been shown that the LPS of Acetobacter pasteurianus, an acetic acid bacterium used in black vinegar manufacturing in Japan, induces a weak inflammatory response (4). From the above, G. hansenii, a Gram-negative bacterium, can be considered to contain LPS as a substance producing a positive limulus reaction, producing a weak inflammatory response.

The structure of LPS in acetic acid bacteria is different from the LPS of Gram-negative bacteria of the family of intestinal bacteria, and it is highly stable under acidic conditions (3). This could mean that there is a small reduction in the activity when heated under acidic conditions, as observed in Pantoea LPS. This can be considered as a useful property in various food fields since the manufacturing process includes heating under acidic conditions.

Ingredients other than acetic acid are considered to be functional ingredients of vinegar (1). In the age-old method of manufacturing vinegar, a bacterial film is formed by the acetic acid bacterial cells, and the maturing process involves the dissolution of the bacterial film. Therefore, besides acetic acid, which a metabolite, involvement of components derived from bacterial cells can be considered as substances responsible for the functionality of vinegar. Hashimoto et al. have shown that LPS is present as a functional ingredient in black vinegar (12), Taniguchi et al. have shown the 

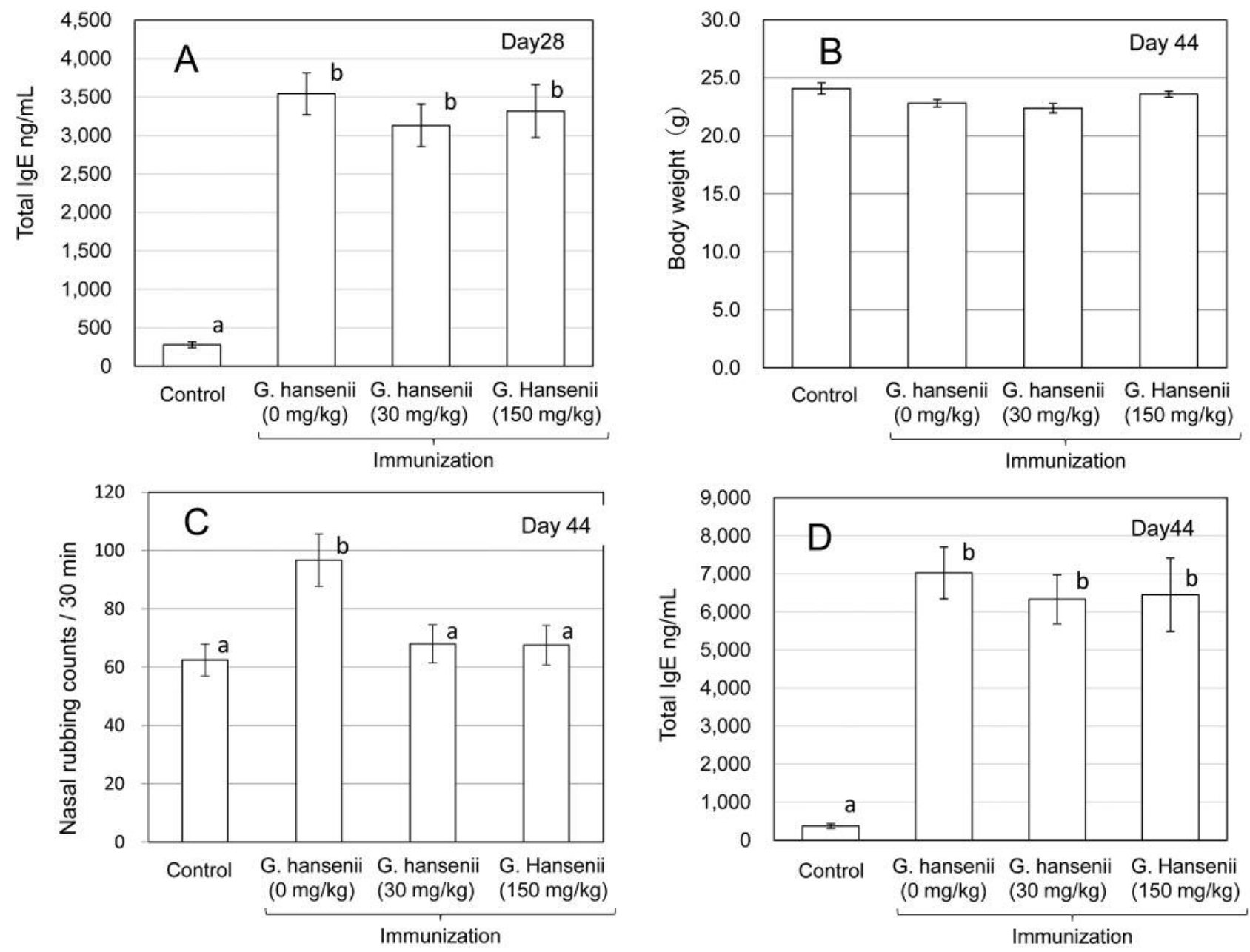

Figure 2. Effect of oral administration of the prepared G. hansenii cell samples on cedar pollen-immunized mice. After 3 intraperitoneal administrations of cedar pollen and alum to mice, cedar pollen was administered intranasally for 2 weeks, and total IgE levels in blood were evaluated (day 28). Killed G. hansenii $(0,30,150 \mathrm{mg} / \mathrm{kg})$ were administered orally with a feeding needle and cedar pollen was administered intranasally for up to 2 weeks (day 30 to 44). On day 44, the frequency of nose scratching following the cedar pollen immunization was counted for 30 min. Blood was collected, and the total IgE levels in serum were evaluated. A: Total IgE levels on day 28 of the non-immunized and immunized control groups (killed G. hansenii 0, 30,150 mg/kg). B: Body weight of the test groups on day 44. C: Frequency of nose scratching over $30 \mathrm{minutes}$ on day 44. D: Total IgE levels in blood on day 44. Columns and bars indicate means and standard deviations $(n=9-16)$, respectively. Different letters indicate statistically significant differences between groups (ANOVA, $p<0.05$ ).

macrophage activation effect of LPS purified from acetic acid bacteria (2), and Amano et al. have shown the preventive effect of oral administration of acetic acid bacteria on cedar pollinosis (11). In this study, G. hansenii was found to mitigate the symptoms of cedar pollinosis (Figure 2). Our results indicate that vinegar produced by the age-old manufacturing method contains LPS as a functional ingredient, which has the effect of mitigating the symptoms of pollen allergy.

Since G. hansenii cells have a history of safe use, experimental conditions were set in this study to investigate the mitigation effect of symptoms following the onset of pollen allergy rather than the preventive effect, assuming their application to people with pollen allergy. In other words, in the present study, mice were given oral doses of G. hansenii bacteria daily after IgE levels increased due to cedar pollen immunization, and at the same time, a model was introduced to evaluate hay fever symptoms by intranasal exposure to cedar pollen. The results are shown in Figure 2C. It was observed that the symptoms of pollen allergy were significantly suppressed by the oral intake of $G$. hansenii, which could be considered to have a therapeutic effect. As no changes in body weight are observed, safety was not considered to be a problem. These facts suggest that 

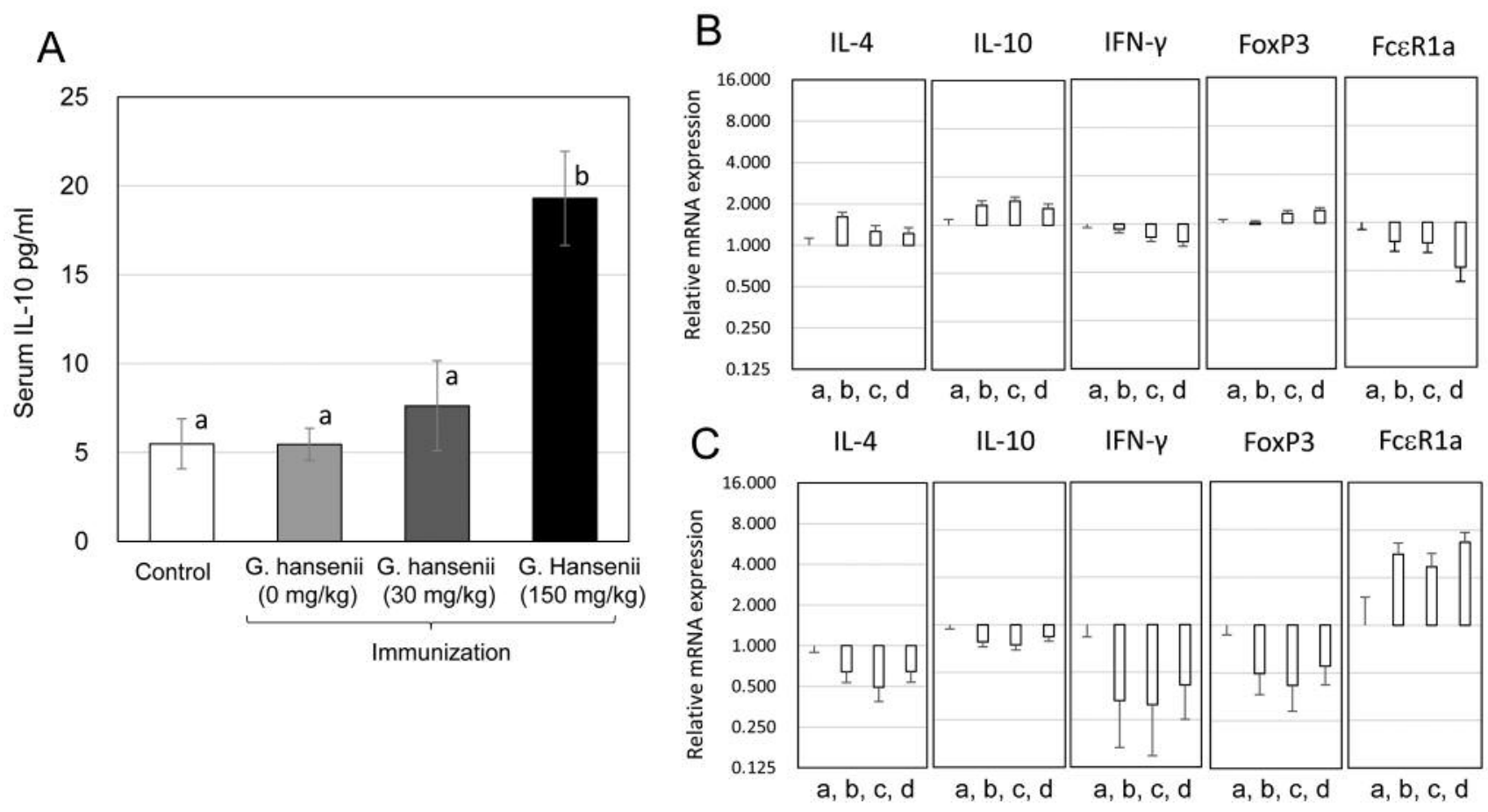

Figure 3. Cytokine analysis of cedar pollen-immunized mice orally administered with the prepared samples of G. hansenii cells. After 3 intraperitoneal administrations of cedar pollen and alum to mice, cedar pollen was administered intranasally for 2 weeks, and then killed G. hansenii $(0,30,150 \mathrm{mg} / \mathrm{kg}$ ) were administered orally with a feeding needle for up to 4 weeks (day 30 to 58) and cedar pollen was administered intranasally for up to 3 weeks (day 37 to 58). On day 58, the collection of blood samples and extraction of Peyer's patches and spleen was performed. A: Serum IL-10 was measured using ELISA. Different letters indicate statistically significant differences between groups (ANOVA, $p<0.01)$. B: RNA was extracted from Peyer's patches, and quantitative RT-PCR was performed. The vertical axis shows the relative amounts of gene expression for the immunized control group (b), immunized + acetic acid bacteria low dosage group (c), and immunized + acetic acid bacteria high dosage group (d) when gene-expression in the non-immunized control group (a) is considered as 1 . The column shows the mean, and the bar shows the SD ( $n=9$ to 16). C: Gene expression of cytokines in the spleen.

oral intake of $G$. hansenii cells can be considered to be a potential a useful diet item to alleviate the symptoms of pollen allergy.

The total levels of IgE in blood were not affected by $G$. hansenii (Figure 2D). An increase in the production of IL10, which is an anti-inflammatory cytokine, was observed in the G. hansenii high-dosage group (Figure 3A), but not in the low-dose group with the pollen allergy suppression effect. These results suggest that IL10 induction contributes to the suppression of pollen allergy symptoms by the oral administration of acetic acid bacteria. Gene expression analysis of Th1 (IFN- $\gamma$ ), Th2 (IL4), the inhibitory system (IL10, FoxP3), and allergy index (FceR1a) genes in Peyer's patches and spleen did not reveal significant changes (Figure $3 \mathrm{~B}$ and $\mathrm{C}$ ). Our results suggested that the primary mechanism by which pollen allergy symptoms are mitigated through oral administration of $G$. hansenii cells is different and will be explored in future studies.

\section{Conflicts of Interest}

The Authors have no conflicts of interest to declare regarding this study.

\section{Authors' Contributions}

TN, and SA performed most experiments under the supervision of CK, GS, and HI. HI provided ideas and supervision. CK conceived the project, provided and funding.

\section{References}

1 Budak NH, Aykin E, Seydim AC, Greene AK and Guzel-Seydim ZB: Functional properties of vinegar. J Food Sci 79: R757-764, 2014. PMID: 24811350. DOI: 10.1111/1750-3841.12434

2 Taniguchi Y, Nishizawa T, Kohchi C, Inagawa H, Yamaguchi T, Nagai S, Tamura A and Soma G: Identification and characterization of lipopolysaccharide in acetic acid bacteria. Anticancer Res 26: 3997-4002, 2006. PMID: 17195448. 
3 Hashimoto M, Ozono M, Furuyashiki M, Baba R, Hashiguchi S, Suda, Y, Fukase K and Fujimoto Y: Characterization of a novel D-glycero-D-talo-oct-2-ulosonic acid-substituted lipid a moiety in the lipopolysaccharide produced by the acetic acid bacterium Acetobacter pasteurianus NBRC 3283. J Biol Chem 291: 2118421194, 2016. PMID: 27539854. DOI: 10.1074/jbc.M116.751271

4 Hashimoto M, Matsumoto T, Tamura-Nakano M, Ozono M, Hashiguchi S and Suda Y: Characterization of outer membrane vesicles of Acetobacter pasteurianus NBRC3283. J Biosci Bioeng 125: 425-431, 2017. PMID: 29208444. DOI: 10.1016/ j.jbiosc.2017.11.006

5 Inagawa $\mathrm{H}$, Kohchi $\mathrm{C}$ and Soma G: Usefulness of oral administration of lipopolysaccharide for disease prevention through the induction of priming in macrophages. Anticancer Res 34: 4497-4501, 2014. PMID: 25075092.

6 Inagawa H, Kobayashi Y, Kohchi C, Zhang R, Shibasaki Y and Soma G: Primed activation of macrophages by oral administration of lipopolysaccharide derived from Pantoea agglomerans. In Vivo 30: 205-211, 2016. PMID: 27107076.

7 Inagawa $\mathrm{H}$, Saika $\mathrm{T}$, Nisizawa $\mathrm{T}$, Kohchi $\mathrm{C}$, Uenobe $\mathrm{M}$ and Soma G: Dewaxed brown rice contains a significant amount of lipopolysaccharide pointing to macrophage activation via TLRs. Anticancer Res 36: 3599-3605, 2016. PMID: 27354629.

8 Inagawa H, Saika T, Nishiyama N, Nisizawa T, Kohchi C, Uenobe $\mathrm{M}$ and Soma G: Dewaxed brown rice feed improves fatty liver in obese and diabetic model mice. Anticancer Res 38 : 4339-4345, 2018. PMID: 29970571. DOI: 10.21873/anticanres. 12734

9 Nakata K, Taniguchi Y, Yoshioka N, Yoshida A, Inagawa H, Nakamoto T, Yoshimura H, Miyake S, Kohchi C, Kuroki M and Soma G: A mixture of Salacia extract and IP-PA1 reduces fasting plasma glucose (FPG) levels and LDL cholesterol levels. Nutr Res Practice 5: 435-442, 2011. PMID: 22125681. DOI: 10.41 62/nrp.2011.5.5.435
10 Nakata Y, Kohchi C, Ogawa K, Nakamoto T, Yoshimura H and Soma G: Effects of 3 months continuous intake of supplement containing Pantoea agglomerans LPS to maintain normal bloodstream in adults: Parallel double-blind randomized controlled study. Food Sci Nutr 20: 197-206, 2017. PMID: 29387379. DOI: $10.1002 / f s n 3.547$

11 Amano $\mathrm{S}$, Inagawa $\mathrm{H}$, Nakata $\mathrm{Y}$, Ohmori $\mathrm{M}$, Kohchi $\mathrm{C}$ and Soma G: Oral administration of lipopolysaccharide of acetic acid bacteria protects pollen allergy in a murine model. Anticancer Res 35: 4509-4514, 2015. PMID: 26168494.

12 Torija MJ, Mateo E, Guillamón JM and Mas A: Identification and quantification of acetic acid bacteria in wine and vinegar by TaqMan-MGB probes. Food Microbiol 27: 257-265, 2010. PMID: 20141944. DOI: 10.1016/j.fm.2009.10.001

13 Rani UM and Appaiah A: Optimization of culture conditions for bacterial cellulose production from Gluconacetobacter hansenii UAC09. Ann Microbiol 61: 781-787, 2011. PMID: 21791961.

14 Weinrauch Y, Katz SS, Munford RS, Elsbach P and Weiss J: Deacylation of purified lipopolysaccharides by cellular and extracellular components of a sterile rabbit peritoneal inflammatory exudate. Innfect Immun 67: 3376-3382, 1999. PMID: 10377115.
Received May 23, 2019

Revised June 20, 2019

Accepted June 21, 2019 